\title{
Staged hybrid repair of mega aortic syndrome: Good...but not great
}

\author{
Nicholas D. Andersen, MD
}

From the Department of Cardiac Surgery, Boston Children's Hospital, Harvard Medical School, Boston, Mass. Disclosures: Author has nothing to disclose with regard to commercial support.

Received for publication July 19, 2017; accepted for publication July 31, 2017; available ahead of print Sept 1, 2017.

Address for reprints: Nicholas D. Andersen, MD, Department of Cardiac Surgery, Boston Children's Hospital, 300 Longwood Ave, Bader 273, Boston, MA 02115 (E-mail: Nicholas.Andersen@ cardio.chboston.org).

J Thorac Cardiovasc Surg 2017;154:1850-1

$0022-5223 / \$ 36.00$

Copyright (c) 2017 by The American Association for Thoracic Surgery

http://dx.doi.org/10.1016/j.jtcvs.2017.07.057

The treatment of panaortic aneurysmal degeneration (or mega aortic syndrome) represents a rare but formidable challenge that requires expertise with all facets of the aortic surgical armamentarium. ${ }^{1}$ In this issue of the Journal, Gkremoutis and colleagues ${ }^{2}$ report their recent results with mega aortic repair at a single institution in Germany. During a 9year period, 15 carefully selected patients (mean age, 53 years) were treated with a 3-stage approach that used a combination of contemporary open and endovascular aortic repair techniques. First, total arch replacement with frozen elephant trunk descending aortic stenting was performed with circulatory arrest and adjunctive cerebral perfusion. Next, a hybrid thoracoabdominal aorta repair was performed in 2 additional stages (stage 2, visceral debranching with or without infrarenal aortic replacement; and stage 3, endovascular completion). Results demonstrated only 1 procedural death, yielding an admirable 93\% survival to hospital discharge. Four additional patients died within a year of surgery, however, yielding a 1-year survival of $66 \%$. Long-term survival continued to decline, and at 5 years the survival statistic had fallen to $28 \%$ (Figure 1).

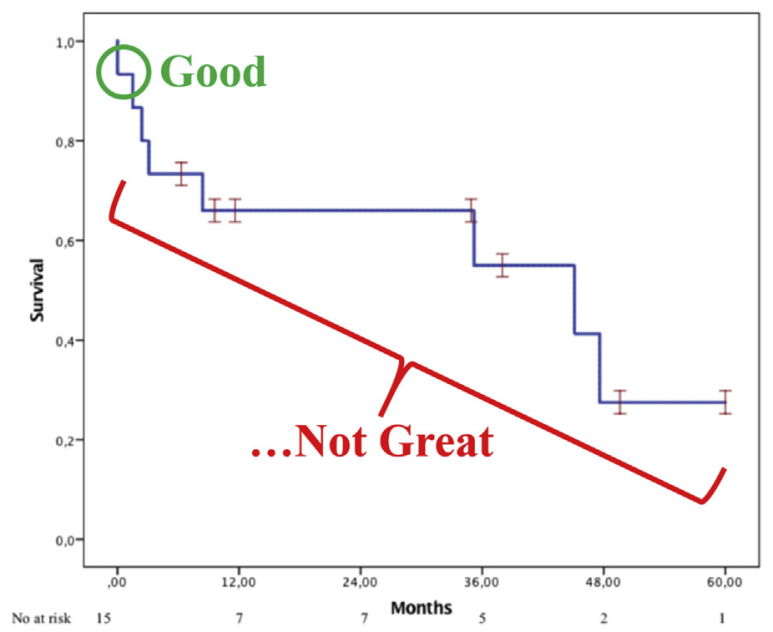

FIGURE 1. Staged hybrid repair of mega aortic syndrome. Outcomes are good, but not great.

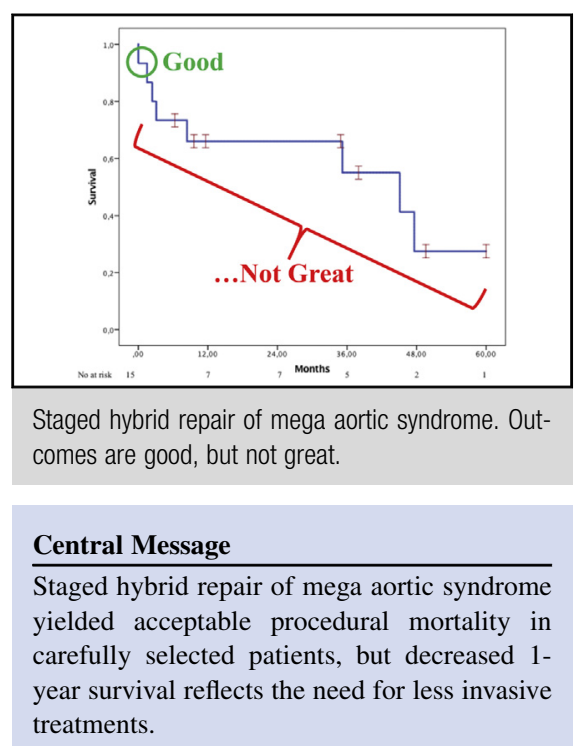

See Article page 1842.

The results of this experience carefully highlight the strengths and weaknesses of the contemporary treatment of mega aortic syndrome. Aortic surgery is considerably safer than in previous decades, and Gkremoutis and colleagues $^{2}$ achieved an impressive procedural mortality lower than $10 \%$ for a daunting 3 -step surgical sequence. The specific approach selected by Gkremoutis and colleagues ${ }^{2}$ has a key advantage relative to conventional open repair: avoidance of a large open thoracoabdominal incision and highaortic crossclamping in lieu of a laparotomy incision for visceral debranching followed by endovascular completion. Nonetheless, the operative sequence remains highly invasive and was associated with significant morbidity in this relatively young patient population. Major complications included bowel ischemia requiring resection (20\%), reoperation for bleeding $(13 \%)$, paraplegia $(7 \%)$, temporary dialysis $(7 \%)$, tracheostomy $(7 \%)$, and pacemaker implantation $(7 \%)$. The physiologic impact of surgery is perhaps most apparent in the 1-year survival statistic. We have learned that a substantial proportion of thoracoabdominal aneurysm repair "survivors" never fully recover from surgery and instead dwindle and fade in nursing facilities, or die of medical complications, after hospital discharge. ${ }^{3}$ Although no patients in this series were known to have died of aortic disease during follow-up, the midterm survival data clearly suggest that the physiologic insult of the operative sequence 
was not trivial and likely contributed to late deaths related to the debilitating effects of 3 major operations.

Of course, the ideal solution to this problem involves a single-stage, minimally invasive replacement of the entire diseased aorta that avoids the insults of sternotomy, thoracotomy, laparotomy, cardiopulmonary bypass, and circulatory arrest, and the risk of interstage death or attrition. As branched and fenestrated endograft technology for both the aortic arch and thoracoabdominal aorta gradually expands and enters the mainstream, this now somewhat implausible solution will eventually become a muchneeded reality. ${ }^{4}$ Even then, however, not all patient anatomies will be amenable to total endovascular repair, and innovation in hybrid techniques will still be required to create disease-free areas of proximal and distal stent graft landing zone in certain patients, including those with connective tissue diseases.

\section{References}

1. Shah AA, Bhattacharya SD, McCann RL, Hughes GC. Pan-aortic hybrid treatment of mega-aorta syndrome. J Vasc Surg. 2011;53:1398-401.

2. Gkremoutis A, Zierer A, Schmitz-Rixen T, El-Sayed Ahmad A, Kaiser E, Keese M, et al. Staged treatment of mega aortic syndrome using the frozen elephant trunk and hybrid thoracoabdominal repair. J Thorac Cardiovasc Surg. 2017;154:1842-9.

3. Rigberg DA, McGory ML, Zingmond DS, Maggard MA, Agustin M, Lawrence PF, et al. Thirty-day mortality statistics underestimate the risk of repair of thoracoabdominal aortic aneurysms: a statewide experience. J Vasc Surg. 2006; 43:217-22; discussion 223

4. Kitagawa A, Greenberg RK, Eagleton MJ, Mastracci TM, Roselli EE. Fenestrated and branched endovascular aortic repair for chronic type B aortic dissection with thoracoabdominal aneurysms. J Vasc Surg. 2013;58: 625-34. 